\title{
Gaudiebility and Psychopathological Symptoms in the Mexican Population
}

\author{
Joel Omar González-Cantero*, Víctor Hugo González-Becerra, Laura Miriam Ramírez-Zamora, \\ José Guadalupe Salazar-Estrada, Jahaziel Molina del Rio, Diana Ortiz Sánchez, \\ Anaid Amira Villegas Ramírez
}

Behavioural and Health Research Centre, University of Guadalajara, Ameca, México

Email: *joel.gonzalez@academicos.udg.mx

How to cite this paper: González-Cantero, J. O., González-Becerra, V. H., RamírezZamora, L. M., Salazar-Estrada, J. G., del Rio, J. M., Sánchez, D. O., \& Ramírez, A. A. V. (2018). Gaudiebility and Psychopathological Symptoms in the Mexican Population. Psychology, 9, 925-933.

https://doi.org/10.4236/psych.2018.95057

Received: April 9, 2018

Accepted: May 7, 2018

Published: May 10, 2018

Copyright $\odot 2018$ by authors and Scientific Research Publishing Inc. This work is licensed under the Creative Commons Attribution International License (CC BY 4.0).

http://creativecommons.org/licenses/by/4.0/

(c) (i) Open Access

\begin{abstract}
It is necessary to identify variables of Positive Psychology related to mental health and well-being. Therefore, the aim of this study was to identify the relationship between gaudiebility and psychopathological symptoms in the Mexican population. The participants were 285 Mexicans between 14 and 78 years old. Gaudiebility was measured with the Gaudiebility Scale of Padrós \& Fernández-Castro and psychopathological symptoms with the Symptom Checklist-90 (SCL-90). Results show a statistically significant and negative correlation $(-.324, p<.001)$ in which the higher the gaudiebility, the lower the level of Global Severity Index. Although more research is needed, results suggest that the development of gaudiebility could be a protective factor for mental health.
\end{abstract}

\section{Keywords}

Positive Affect, Psychopathological Symptoms, Enjoyment, Mental Health, Positive Psychology

\section{Introduction}

There is consistent scientific evidence that certain environmental factors, classified as psychosocial adversity have a stronger association than genetic factors with negative mental health outcomes (Palacios, 2015). For example, Catalá-López, Gènova-Maleras, Álvarez-Martín, Fernández \& Morant-Ginestar (2013) pointed out that the burden of disease in adolescents and young people was primarily attributable to mental and neurological disorders. In Mexico, depressive and anxious syndromes, epilepsy, dementia, schizophrenia, addictions and disorders of child development, have increased during the last years (Souza 
\& Cruz, 2010).

As such, this depends on several factors; one of them could be the dominance of the biomedical model advocating that the criterion for a person to be considered mentally healthy was not a diagnosis of a psychological disorder. In contrast, the World Health Organization (2014) points out that mental health is "a state of being in which every individual realizes his own abilities, can cope with the normal stresses of life, can work productively and fruitfully, and is able to contribute to their community". This definition implies not only that mental health goes beyond the absence of any psychological disorder, but also that, people must have skills that will help them to tackle adaptive everyday stressors and take an active role regarding the solution of social problems in their environment.

From the perspective of Positive Psychology, it is necessary to identify variables which are related to the maintenance of mental health and increased well-being of people who are at risk of having a psychological disorder but have not developed it yet. Positive Psychology offers new approaches to strengthen psychological resistance and the promotion of mental health (Kobau et al., 2011; Pietrowsky \& Mikutta, 2012). In a way, Positive Psychology promotes the hedonistic view of life, which becomes better as we enjoy it more (Veenhoven, 2003).

Within the framework of Positive Psychology to promote mental health is the concept of gaudiebility. This concept has a background dating back to ancient Greece, where the so-called hedonist was studying the pursuit of pleasure and the suppression of pain as a goal or reason for being. In addition, it is relevant to highlight the fact that gaudiebility has a more recent background in the concept of "reinforcement sensitivity", according to which individuals with high reinforcement sensitivity show greater interest, persistence and perseverance than those who don't find such reinforcement (Pickering \& Corr, 2008; Pickering, Corr \& Gray, 1999).

Thus, gaudiebility is defined as:

a psychological construct which includes all the processes from the external input to the enjoyment that people might experience, i.e. the set of mediators that regulate enjoyment, to a greater or lesser intensity, in a greater or lesser number of situations and during shorter or longer periods of time; in such a way that a higher level of gaudiebility implies more possibilities that people of enjoying something. Gaudiebility is therefore defined as the measure of the disposition to experience enjoyment that any person can have (Padrós \& Fernández-Castro, 2008: p. 414).

Gaudiebility also has to do with a set of procedures that serve to remove the inadequate control mechanisms involved in avoidance and let the individual work toward a natural relationship and enjoyment regarding the events which can improve their subjective well-being (Montgomery, 2009).

That is why recent research has suggested that levels (higher or lower) of enjoyment and gaudiebility should be key objectives in the processes of interven- 
tion in some mental disorders, such post-traumatic stress disorder (Koenen, Stellman, Sommer, \& Stellman, 2008), addictive behaviours related to sexually transmitted infections (Padrós, Martínez, González, Rodríguez, \& Astals, 2011), and obsessive-compulsive disorders (Macy et al., 2013). Particularly, Padrós, Martínez \& Graff (2014), based on the result of their pilot study, pointed out that a gaudiebility intervention is feasible in patient with mild to moderate major depression because such intervention could be helpful relieving depressive symptoms when it is administered as an adjuvant therapy to conventional antidepressant treatment. Moreover, in another study, people diagnosed with schizophrenia showed lower levels of gaudiebility compared to healthy individuals in the control group (Padrós, Martínez-Medina, \& Cruz, 2011).

Based on a systematic review Sánchez-Teruel \& Robles-Bello (2017) pointed out that psychological aspects modulate gaudiebility above other aspects such as biological, economic, or demographic.

Thus, since there are not yet many studies to verify whether gaudiebility acts as a protective factor against psychopathological symptoms, this study aims to identify the relationship between gaudiebility and psychopathological symptoms in the Mexican population. In addition, an aim is to compare by sex gaudiebility and psychopathological symptoms.

\section{Method}

\section{Participants}

Participants included 285 Mexicans between 14 and 78 years of age $(M=$ 32.13; $S D=13.38$ ). Regarding sex, $36.5 \%$ were men and $63.5 \%$ women. With respect to civil status, $50.9 \%$ were single, $42.8 \%$ married, $2.5 \%$ widowed/widowered, $0.7 \%$ divorced and $3.2 \%$ identified themselves as "other". The scholarship of the sample was distributed as follows: $40.3 \%$ basic education, $36.8 \%$ high school, $21.1 \%$ bachelor's degree and $1.8 \%$ a master's degree or $\mathrm{PhD}$. In employment, $59.3 \%$ of participants worked and $40.7 \%$ did not. And regarding residence, $40.1 \%$ lived in a rural area and $59.9 \%$ in an urban one.

\section{Procedure}

Participants were recruited based on snowball and non-probability sampling. Data collection was conducted through an interview in a single session of 20 - 25 minutes by psychology students who were trained in the implementation of psychometric instruments. The applicators, initially, gave a brief explanation of the purpose of the research and asked those who accepted the intervention to sign the informed consent. Informed consent was based on the Helsinki Declaration and the General Health Law of the United Mexican States in its fifth title "Research for Health" ONLY CHAPTER, Article 100.

\section{Measures}

Socio-demographic Questionnaire. Socio-demographic data were collected from the participants through a structured questionnaire developed for this specific study. 
Gaudiebility Scale. Gaudiebility was assessed with the Gaudiebility Scale (Padrós\& Fernández-Castro, 2008) composed of 23 items with five response options ranging from "complete disagreement" (0) to "to complete agreement" (4). The total score is obtained from the sum of the 23 items (15, 19 and 22 are valued in reverse order), and may vary from 0 to 92 . A higher score indicates a higher level of gaudiebility. There is satisfactory evidence of the internal consistency of Cronbach's alpha between .84 and .86 , and a test-retest reliability of $r$ $=.741$ over a period of two months in Mexican population (Padrós-Blázquez, Herrera-Guzmán, \& Gudayol-Ferré, 2012).

Symptom Checklist-90 (SCL-90). SCL 90 was developed by Derogatis, Lipman \& Covi in 1973. It is a 90-item self-report inventory that assesses the level of psychopathological symptoms experienced by the subject. Items are comprised of nine factors and three global indexes of psychological distress. The nine factors are: Somatization (SOM), Obsessive-Compulsive (O-C), Interpersonal Sensitivity (I-S), Depression (DEP), Anxiety (ANX), Hostility (HOS), Phobic Anxiety (PHOB), Paranoid Ideation (PAR) Ideation and Psychoticism (PSY), while the three global indexes of psychological distress are: the Global Severity Index (GSI), the Positive Symptom Distress Index, (PSDI), and the Positive Symptom Total (PST). The checklist is a Likert-type scale with five response options ranging from "nothing" to "a lot". It can be answered by a person with a primary level of schooling, but if the person shows difficulties reading the examiner can read the reagents. This inventory assesses symptom patterns present in individuals and can be used in community work as clinical diagnosis. In this study, the version validated for the Mexican population by Cruz López, Blas, González \& Chavez (2005) was used; these authors reported good internal consistency values (Cronbach's alphas $>.7-.85$ ) in nine of the eleven factors with only Hostility and Paranoid Ideation reaching an acceptable value $(>.6-<.7)$.

\section{Statistical analysis}

The analyses were performed using the IBM SPSS Statistics software package, version 24 . To evaluate the relationship between gaudiebility and psychopathological symptoms, two analyses were conducted: a Pearson correlation and a linear regression. Also, a t-Student was used to compare men's and women's gaudiebility and psychopathological symptoms. Finally, a reliability test was performed for Gaudiebility Scale and Symptom Checklist-90 with Cronbach's alpha.

\section{Results}

The results show a negative and significant correlation between gaudiebility and the Global Severity Index and all the factors of the SCL-90, as can be seen in Table 1. The highest correlations of gaudiebility were with Depression and Obsessive-Compulsive factors. On the other hand, the lowest correlation was with $\mathrm{Pa}$ ranoid Ideation.

The correlations between gaudiebility and psychopathological symptoms (it 
was used only the Global Severity Index) allowed the definition of the design and subsequent adjustment of the linear regression model used. The 10.5 of the total variance of psychopathological symptoms is explained by the gaudiebility $\left(\mathrm{R}^{2}\right.$ $=.105)$. The analysis of variance indicates the existence of an appropriate adjustment of the model $(\mathrm{F}=33.18, p<.0001)$ as can be seen in Table 2 .

Gaudiebility mean was $63.84(S D=11.76)$; it was higher in men than in women, but it was not statistically significant. The results by factor are shown in Table 3.

In relation to theSymptom Checklist-90(SCL 90) instrument, a Global Severity Index and a score for each factor was obtained (see Table 3). Results indicate that the sample has a mean Global Severity Index of .72 $(S D=.53)$ and a statistically significant difference between men and women stands out.

Regarding the Symptom Checklist-90 (SCL 90) instrument, in this study it yielded a general alpha of .972 , while the Gaudiebility Scale yielded a general Cronbach's alpha of .856 .

Table 1. Correlation between gaudiebility and symptoms of psychopathology.

\begin{tabular}{cccccccccc}
\hline GSI & SOM & O-C & I-S & DEP & ANX & HOS & PHOB & PAR & PSY \\
\hline$-.324^{*}$ & $-.241^{*}$ & $-.327^{*}$ & $-.299^{*}$ & $-.334^{*}$ & $-.250^{*}$ & $-.235^{*}$ & $-.239^{*}$ & $-.191^{*}$ & $-.258^{*}$ \\
\hline
\end{tabular}

GSI = Global Severity Index; SOM = Somatization; O-C = Obsessive-Compulsive; I-S = Interpersonal Sensitivity; DEP = Depression; ANX = Anxiety; HOS $=$ Hostility; PHOB $=$ Phobic Anxiety; PAR = Paranoid Ideation; PSY = Ideation and Psychoticism. ${ }^{*}(p<.001)$.

Table 2. Model summary of linear regression.

\begin{tabular}{ccccccccccc}
\hline Model & $\mathrm{R}$ & R Square & Adjusted R Square & $\begin{array}{c}\text { Std. Error of the } \\
\text { Estimate }\end{array}$ & R Squared Change & F Change & df1 & df2 & Sig. F Change \\
\hline 1 & $.324^{\mathrm{a}}$ & .105 & .102 & .50914 & .105 & 33.183 & 1 & 283 & .001 \\
\hline
\end{tabular}

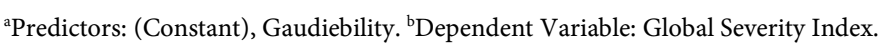

Table 3. Descriptive measures of gaudiebility and symptoms of psychopathology.

\begin{tabular}{|c|c|c|c|c|}
\hline & Men $(n=104)$ & Women $(n=181)$ & Total $(n=285)$ & Gender difference \\
\hline & Mean (SD) & Mean (SD) & Mean (SD) & (Student's t Test) \\
\hline Gaudiebility & $64.08(12.70)$ & $63.70(11.21)$ & $63.84(11.76)$ & $.250(p=.803)$ \\
\hline Global Severity Index & $.60(.43)$ & $.79(.57)$ & $.72(.53)$ & $-3.188(p=.002)$ \\
\hline Somatization & $.48(.50)$ & $.75(.64)$ & $.65(.61)$ & $-3.925(p=.001)$ \\
\hline Obsessive-Compulsive & $.93(.61)$ & $1.06(.71)$ & $1.01(.68)$ & $-1.596(p=.112)$ \\
\hline Interpersonal Sensitivity & $.64(.53)$ & $.88(.68)$ & $.79(.64)$ & $-3.397(p=.001)$ \\
\hline Depression & $.56(.49)$ & $.85(.70)$ & $.74(.65)$ & $-4.089(p=.001)$ \\
\hline Anxiety & $.53(.48)$ & $.76(.66)$ & $.67(.61)$ & $-3.239(p=.001)$ \\
\hline Hostility & $.64(.64)$ & $.71(.67)$ & $.69(.66)$ & $-.888(p=.375)$ \\
\hline Phobic anxiety & $.19(.34)$ & $.47(.67)$ & $.37(.59)$ & $-4.580(p=.001)$ \\
\hline Paranoid Ideation & $.74(.67)$ & $.81(.72)$ & $.78(.70)$ & $-.751(p=.454)$ \\
\hline Psychoticism & $.46(.45)$ & $.53(.54)$ & $.50(.51)$ & $-1.151(p=.251)$ \\
\hline
\end{tabular}




\section{Discussion}

The present study contributes to gaudiebility literature-particularly to the clarification of the relationship between gaudiebility and symptoms of psychopathology.

In that way, this study shows a negative and statistically significant correlation between gaudiebility and the Global Severity Index and all the factors of the SCL-90; however, the coefficients are low. Despite this, it is useful to identify that it is possible to increase gaudiebility levels to decrease psychopathological symptoms because this one last variable, according to Lamers, Westerhof, Glas, \& Bohlmeijer (2015), has a bidirectional relationship with positive mental health, meaning that the reduction of psychopathological symptoms can increase mental health.

The moderate results of this study match with the results of other studies. For example, Gallagher \& Lopez (2007) found that exploration and absorption (components of curiosity which is a variable in the gaudiebility construct) have moderate positive associations with well-being. Another case is the study of Wellenzohn, Proyer \& Ruch (2016), who tested the effects of humour (a component of gaudiebility) on happiness and depression with five humor-based activities in a placebo-controlled, self-administered online Positive Psychology intervention study and pointed out that all the humor-based interventions were also effective in ameliorating depressive symptoms, but only directly after the intervention and generally with smaller effects.

In the same sense, Padrós, Martinez, Martin \& Curcoll (2013), in a study with patients with spinal cord injury, found that such patients experienced a post-traumatic growth, improving their gaudiebility, although the authors point out that these results should be taken with caution, since more studies are required.

It is relevant that there were no statistically significant differences in gaudiebility by sex. This could give rise to the fact that gaudiebility is measured by clinical variables, not by socio-demographic ones.

With respect to SCL-90, several studies obtained results different from those of this study. For example, González-Santos, Mercadillo, Graff \& Barrios (2007) reported .50 in the GSI for Mexicans with a mean age of 30 and Rivera-Ledesma, Caballero, Pérez \& Montero-López (2013) also pointed out, a GSI of .51 for men and .61 for women. Both cases are different from the results of this study, in which the Global Severity Index was .72. However, in this study, women also receivedhigher scores than men in factors such as Somatization and Depression (González-Santos, Mercadillo, Graff, \& Barrios, 2007; Rivera-Ledesma, Caballero, Pérez, \& Montero-López, 2013). These differences could be associated with ruminant thoughts characteristic in somatization and depression.

In accordance with the foregoing, it is necessary to continue the assessment of the role of gaudiebility on individual well-being and consequently its role as a protective factor against psychopathological symptoms. 


\section{Conclusion}

This study contributes to the scientific literature about gaudiebility and its relationship with symptoms of psychopathology in Mexican population. A negative and low association between these variables was found. These findings could help to develop interventions for people focus on the present and enjoy it.

\section{Limitations}

One of the limitations of the present study is that the population was general. Also, was a limitation that the SCL-90 is a screening test. As a result, it will be necessary to investigate clinical populations, particularly those of people with mood disorders, psychotic and anxiety among other. Another problem was the heterogeneity of the participants, since there were many variants: age, sex, marital status, and socio-economic level. Furthermore, this study did not include a child population, in which there may be differences in contrast with adults. In addition, longitudinal studies are needed to assess the consistency of the higher level of gaudiebility with minor symptoms of psychopathology. It is suggested that gaudiebility be studied in a homogenous population, for example in a clinical population, to control and, therefore, identify the variables that could be associated with this construct. Finally, it is necessary to assess the interaction of two or more variables modulating the gaudiebility and, for example, the study of gaudiebility in a homogenous population, and their convergence and divergence with other constructs such as psychological well-being and resilience.

\section{Acknowledgements}

To the Science and Technology National Council of Mexico, who granted a scholarship (Scholarship number 374769) to the first author.

\section{Disclosure Statement}

No potential conflict of interest was reported by the authors.

\section{References}

Catalá-López, F., Gènova-Maleras, R., Álvarez-Martín, E., Fernández, N., \& Morant-Ginestar, C. (2013). Carga de enfermedad en adolescentes y jóvenes en España. Revista de Psiquiatría y Salud Mental, 6, 80-85. https://doi.org/10.1016/j.rpsm.2012.07.002

Cruz, C. S., López, L., Blas, C., González, L., \& Chávez, R. A. (2005). Datos sobre la validez y confiabilidad de la Symptom Checklist-90 (SCL-90) en una muestra de sujetos mexicanos. Salud Mental, 28, 72-81.

Gallagher, M. W., \& Lopez, S. (2007). Curiosity and Well-Being. The Journal of Positive Psychology, 2, 236-248. https://doi.org/10.1080/17439760701552345

González-Santos, L., Mercadillo, R. E., Graff, A., \& Barrios, F. A. (2007). Versión computarizada para la aplicación del Listado de Síntomas 90 (SCL 90) y del Inventario de Temperamento y Carácter (ITC). Salud Mental, 30, 31-40.

Kobau, R., Seligman, M. E. P., Peterson, C., Diener, E., Zack, M., Chapman, D., \& 
Thompson, W. (2011). Mental Health Promotion in Public Health: Perspectives and Strategies from Positive Psychology. American Journal of Public Health, 101, 1-9. https://doi.org/10.2105/AJPH.2010.300083

Koenen, K. C., Stellman, S. D., Sommer, J. F., \& Stellman, J. M. (2008). Persisting Posttraumatic Stress Disorder Symptoms and Their Relationship to Functioning in Vietnam Veterans: A 14-Year Follow-Up. Journal of Traumatic Stress, 21, 49-57. https://doi.org/10.1002/jts.20304

Lamers, S. M. A., Westerhof, G. J., Glas, C. A. W., \& Bohlmeijer, E. T. (2015). The Bidirectional Relation between Positive Mental Health and Psychopathology in a Longitudinal Representative Panel Study. The Journal of Positive Psychology, 10, 553-560. https://doi.org/10.1080/17439760.2015.1015156

Macy, A., Theo, J., Kaufmann, S., Ghazzaoui, R., Pawlowski, P., Fakhry, H. et al. (2013). Quality of Life in Obsessive Compulsive Disorder. CNS Spectrums, 18, 21-33. https://doi.org/10.1017/S1092852912000697

Montgomery, W. (2009). Mindfulness y gaudibilidad: Categorías en terapia de conducta para tratar la evitación experiencial. Revista de Psicología de la Universidad Inca Garcilaso de la Vega, 1, 55-61.

Padrós, F., \& Fernández-Castro, J. A. (2008). A Proposal to Measure a Modulator of the Experience of Enjoyment: The Gaudiebility Scale. International Journal of Psychology and Psychological Therapy, 8, 413-430.

Padrós, F., Martínez, M. P., Martín, C., \& Curcoll, M. L. (2013). Nivel de gaudibilidad en pacientes con lesión en la médula espinal. Psicología y Salud, 23, 97-102.

Padrós, F., Martínez, P., \& Graff, A. (2014). Gaudiebility Group Therapy in Depressed Patients: A Pilot Study. International Journal of Psychology and Psychological Therapy, 14, 59-69.

Padrós, F., Martínez-Medina, M. P., \& Cruz, M. A. (2011). Nivel de gaudibilidad en pacientes esquizofrénicos: un estudio piloto. Salud Mental, 34, 525-529.

Padrós, M., González, R., \& Astals (2011). Estudio del nivel de gaudibilidad en pacientes con diagnóstico de trastorno por dependencia de sustancias. Psiquis, 20, 64-69.

Padrós-Blázquez, F., Herrera-Guzmán, I., \& Gudayol-Ferré, E. (2012). Propiedades psicométricas de la Escala de Gaudibilidad en una Población Mexicana. Evaluar, 12, 1-20.

Palacios, L. (2015). Adversidad psicosocial, salud mental y suicidio en adolescentes: Estamos haciendo lo suficiente para atender a esta población? Salud Mental, 38, 309-310.

Pickering, A. D., \& Corr, P. J. (2008). J.A. Gray's Reinforcement Sensitivity Theory (RST) of Personality. In G. Boyle, G. Matthews, \& D. Saklofske (Eds.), The SAGE Handbook of Personality: Theory and Assessment Personality Measurement and Testing (Vol. 2, pp. 239-255). London, New Delhi \& Thousand Oaks: Sage.

Pickering, A. D., Corr, P. J., \& Gray, J. A. (1999). Interactions and Reinforcement Sensitivity Theory: A Theoretical Analysis of Rusting and Larsen (1997). Personality and Individual Differences, 26, 357-365.

Pietrowsky, R., \& Mikutta, J. (2012). Effects of Positive Psychology Interventions in Depressive Patients-A Randomized Control study. Psychology, 3, 1067-1073. https://doi.org/10.4236/psych.2012.312158

Rivera-Ledesma, A., Caballero, N. P., Pérez, I. N., \&Montero-López, M. (2013). SCL-90 R: Distrés psicológico, género y conductas de riesgo. Universitas Psychologica, 12, 105-118. 
Sánchez-Teruel, D., \& Robles-Bello, M. A. (2017). La Gaudibilidad y el bienestar subjetivo en la salud: Una revisión sistemática. Revista Latinoamericana de Psicología Positiva, 3, 11-23.

Souza, M., \& Cruz, D. (2010). Salud mental y atención psiquiátrica en México. Revista de la Facultad de Medicina de la UNAM, 53, 17-23.

Veenhoven, R. (2003). Arts of Living. Journal of Happiness Studies, 4, 373-384. https://doi.org/10.1023/B:JOHS.0000005773.08898.ae

Wellenzohn, S., Proyer, R. T., \& Ruch, W. (2016). Humor-Based Online Positive Psychology Interventions: A Randomized Placebo-Controlled Long-Term Trial. The Journal of Positive Psychology, 11, 584-594. https://doi.org/10.1080/17439760.2015.1137624

World Health Organization (2014). Mental Health: A State of Well-Being. http://www.who.int/features/factfiles/mental_health/en/ 